RASĀYAN J. Chem.

Vol. 12 | No. 4 |1857 - 1863| October - December | 2019 ISSN: 0974-1496 | e-ISSN: 0976-0083 | CODEN: RJCABP

\title{
PREPARATION OF HYDROGEL NANOCOMPOSITE CONTAINING GOLD NANOPARTICLES WITH UNIQUE SWELLING/DESWELLING PROPERTIES
}

\author{
E.R.Wikantyasning ${ }^{1, *}$, M.Mutmainnah ${ }^{1,2}$, Z.Cholisoh $^{1}$, I.Hairunisa $^{3}$, \\ M.F.A. Bakar ${ }^{4}$ and M. Da'i ${ }^{1}$ \\ ${ }^{1}$ Faculty of Pharmacy, Universitas Muhammadiyah Surakarta, Jl. A. Yani Tromol Pos 1, \\ Pabelan, Kartasura, Sukoharjo, 57162, Indonesia \\ ${ }^{2}$ Department of Pharmacy, Stikes Muhammadiyah Manado, Jl. Pipit No. 3 Lingk. VI Kel. \\ Malendeng Kec. Paal 2 Kota Manado, Sulawesi Utara, 95128, Indonesia \\ ${ }^{3}$ Faculty of Health and Pharmacy, Universitas Muhammadiyah Kalimantan Timur, Jl. Ir. H. \\ Juanda No 15 Samarinda, 75243, Indonesia \\ ${ }^{4}$ Faculty of Applied Sciences and Technology, Universiti Tun Hussein Onn Malaysia (UTHM), \\ Hub Pendidikan Tinggi Pagoh, KM1, 84600, Muar, Johor, Malaysia \\ *E-mail: erindyah.rw@ums.ac.id
}

\begin{abstract}
Nanosensor based on color changes to environmental changes is developing very rapidly nowadays. The aim of this study was to prepare responsive-hydrogel incorporating gold nanoparticles (AuNPs) and cysteine. Gold nanoparticles were self-assembled with poly(acrylic acid) and cysteine, which were characterized by UV-Vis spectrophotometer, zeta potential was measured by particle size analyzer (PSA), and characteristic of particles was portrayed using TEM. The results showed that the size of the nanoparticles produced is $13.27 \pm 2.43 \mathrm{~nm}$. It was proven that the change in color of the nano-produced particles was resulted from swelling and shrinking of the sensitive-hydrogel that changed the distance of the AuNPs triggered by different $\mathrm{pH}$. This nanosensor was successfully embedded into a hydrogel and showed a unique swelling/deswelling properties as a response to $\mathrm{pH}$ changes.
\end{abstract}

Keywords: Nanoparticles, Sensor, Responsive Hydrogel

(c) RASĀYAN. All rights reserved

\section{INTRODUCTION}

Nanocomposites of responsive polymer and nanoparticles are of increasing interest and importance as the basis for forming sensors. ${ }^{1,2}$ An optical signal or color transition could be a result of the combination of smart polymers and metal nanoparticles (gold or silver nanoparticles). The conformational change in the responsive polymers to respond stimuli will alter the interaction of nanoparticles, thus affect the plasmonic oscillations of the metal nanoparticles. The changes in the LSPR (Localized Surface Plasmon Resonance) band have been exploited for optical sensing and colorimetric assays. ${ }^{3,4}$

Colorimetric sensors prepared using gold nanoparticles capped with $\mathrm{pH}$-responsive polymers have studied intensively. Color changes on such nanoparticles could be observed because of their quick response to different stimuli, such as temperature, salts, $\mathrm{pH}$, or biomolecules. ${ }^{5,6}$ Liu et al. (2010) have been developed a pH-responsive AuNPs capped with hyperbranched polyethyleneimine terminated with isobutyric amide groups. The AuNPs nanocomposites show a reversible color transition from clear red, clear purple and turbid red when exposed to different temperature, $\mathrm{pH}$ and $\mathrm{NaCl}$ concentration. ${ }^{7}$ Previous study by Brubaker et al. (2016) which evaluated the effectiveness of poly(acrylic acid) (PAA) coated AuNPs detecting $\mathrm{pH}$ changes in solution also showed the similar results. The PAA coated AuNPs were able to

Rasayan J. Chem., 12(4), 1857-1863(2019)

http://dx.doi.org/10.31788/RJC.2019.1245209

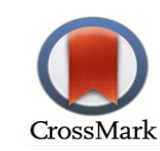


RASĀYAN J. Chem.

Vol. 12 | No. 4 |1857 - 1863| October - December | 2019

distinguish between solutions of $\mathrm{pH} 4$, water and $\mathrm{pH} 10$, which were described by the shifts in the peak of absorbance spectra and changes in optical properties of the solution. ${ }^{8}$

A responsive hydrogel shows volume phase transition reversibly when triggered by small changes in environmental factors, such as temperature, salt type, $\mathrm{pH}$, solvent, electric field, light, high pressure, or biochemical agents. Their applications biomedical field as controlled drug release carriers, diagnostics assay, actuators, or antibacterial materials, make hydrogels an important class of materials. Specifically, in biosensor applications, it is well-known that hydrogels can be used in the fabrication of miniaturized devices with fast response times. ${ }^{9,10}$

Hydrogel-nanoparticles composites offer the potential application in the biomedical field. Combining these materials give advantages such as increasing the mechanical strength of the hydrogel and preventing the aggregation of the nanoparticles. ${ }^{11,12}$ However, the exploitation of responsive hydrogels containing AuNPs as colorimetric sensors are limited, primarily due to the opaque nature of many responsive hydrogels at the shrinking state. A plasmonic device for sensing protein has been developed using AuNPs-loaded stimuli-responsive hydrogels. The shifted of plasmonic bands was observed when the device detected protein in aqueous solution up to $10 \mathrm{ng} / \mathrm{mL} .{ }^{13}$

Agarose is a natural polymer derived from marine algae. This polysaccharide has low toxicity and biocompatible therefore has wide application in the biomedical area. Agarose has a macroporous matrix that permeable for macromolecules with high molecular weight. The other advantages of agarose are the high gel strength so that the hydrogel with good sieving and anti-convective properties can be made by less than $1 \%$ of agarose, and also thermo-reversible with low gelling and melting temperature. ${ }^{14}$ Liu, et al. reported a pH-responsive assembly of charged AuNPs capped with bis(p-sulfonatophenyl)phenylphosphine (BSPP) ligands in $2 \%$ of agarose gel can tune plasmon coupling reversibly. The electrostatic interactions of the AuNPs in different temperature results in a reversible optical property change of the because of the assembly of AuNPs when the temperature of the system was in the range of $5-40^{\circ} \mathrm{C} .{ }^{15}$

In this study, we reported the preparation of agarose hydrogel incorporating gold nanoparticles crosslinked by pH-sensitive polymer poly(acrylic acid). The application of the smart hydrogel for the detection of pathogenic bacteria was also evaluated.

\section{EXPERIMENTAL}

\section{Materials}

Acrylic acid, Gold(III) chloride hydrate $\left(\mathrm{HAuCl}_{4} \cdot \mathrm{xH}_{2} \mathrm{O}\right)$, tribasic sodium citrate, tetrahydrofuran (THF), azobisisobutyronitrile (AIBN) 12\%, agarose, $\mathrm{HCl}, \mathrm{NaOH}$, cysteine were purchased from Sigma-Aldrich.

\section{Synthesis of Gold Nanoparticles (AuNPs)}

AuNPs were synthesized using a chemical reduction method as described previously. ${ }^{16}$ The AuNPs were then characterized by UV-Vis spectrophotometry (Genesys 10S) and Transmission Electron Microscopy (JEOL JEM-1400).

\section{Synthesis of Poly(acrylic acid) (PAA)}

Poly(acrylic acid) (PAA) was synthesized by RAFT polymerization. The chain transfer agent for RAFT polymerization was synthesized according to Bivigou-Koumba et al. (2009). ${ }^{17}$ PAA was collected after dialysis to eliminate the remained monomer and was then characterized by 1H-NMR (Jeol Resonance 400 $\mathrm{MHz})$.

\section{Preparation of Hydrogel-Cysteine-AuNPs-PAA}

One (1) $\mathrm{mL}$ of $1 \mathrm{mM}$ AuNPs was added with $20-200 \mu \mathrm{L}$ of PAA and cysteine solution (CAuNPs-PAA). The peak of absorbance, $\mathrm{pH}$-transition point, the reversibility of the color change and the zeta potential (Horriba scientific SZ 100) of the solution were then determined. The agarose in the concentration of $0.25-2 \%$ was mixed with the solution of CAuNPs-PAA and heated until dissolved. The mixed solution was left at room temperature until the gel was formed. The formed hydrogel-CAuNPs-PAA was 
RASĀYAN J. Chem.

Vol. 12 | No. 4 |1857 - 1863| October - December | 2019

characterized for the maximum wavelength, the $\mathrm{pH}$ transition point, and color change reversibility at $\mathrm{pH} 2$ and $\mathrm{pH} 12$ using a UV-Vis spectrophotometer (Genesys 10).

\section{Detection of $E$. coli Bacteria in vitro}

E. coli bacteria with a concentration of $10^{1}, 10^{2}, 10^{4}, 10^{6}, 10^{8}, 12 \times 10^{8} \mathrm{CFU} / \mathrm{mL}$ was added into solution of CAuNPs-PAA and incubated for 17 hours. The visible spectra and the shifting of the maximum wavelength of the solution were recorded using a UV-Vis spectrophotometer (Genesys 10). The binding of the CAuNPs-PAA on the surface of bacteria was observed using TEM (JEOL JEM-1400).

\section{Properties of AuNPs-PAA}

\section{RESULTS AND DISCUSSION}

The synthesis of AuNPs resulted in a rubies color colloidal, indicated small particles in nanometer range. ${ }^{16}$ Gold chloride reduction with sodium citrate resulted in spherical gold nanoparticles with average diameters of $13.27 \pm 2.43 \mathrm{~nm}$ (Fig.-1B) that are stable, because of repulsive electrostatic forces of nanoparticles in the colloid suspension. This property is a special characteristic of AuNPs and is not owned by its bulk material. The UV-Vis spectrum showed the characteristic band of gold nanoparticles SPR (surface plasmon resonance) which peaked at $523 \mathrm{~nm}$ (Fig.-1A).
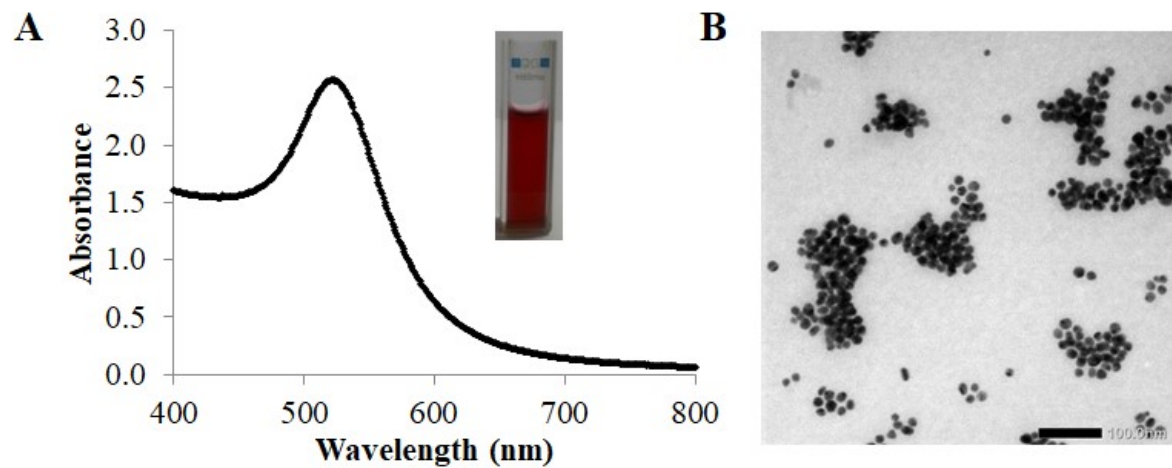

Fig.-1: (A) UV-Visible Spectra and (B) the TEM Image of Produced Gold Nanoparticles

Poly(acrylic acid) PAA is a weak acid polymer that is responsive to changes in environmental $\mathrm{pH}^{8}{ }^{8}$ The pH-responsive polymer in this study was synthesized by the RAFT (Reversible Addition-Fragmentation Chain Transfer) method. RAFT polymerization resulted in PAA with a yield of $68 \%$. The advantage of using this RAFT agent is that the obtained polymer would have thiol groups on both sides. Thiol group has been utilized for capping agent of noble metal nanoparticles, due to high affinity to the surface of nanoparticles. ${ }^{18}$ The H-NMR spectra of PAA are presented in Fig. -2 which showed that the polymer peaked at 3.0-4.5 ppm, and the disappearing of monomer peaked at 5.8-6.2 ppm.

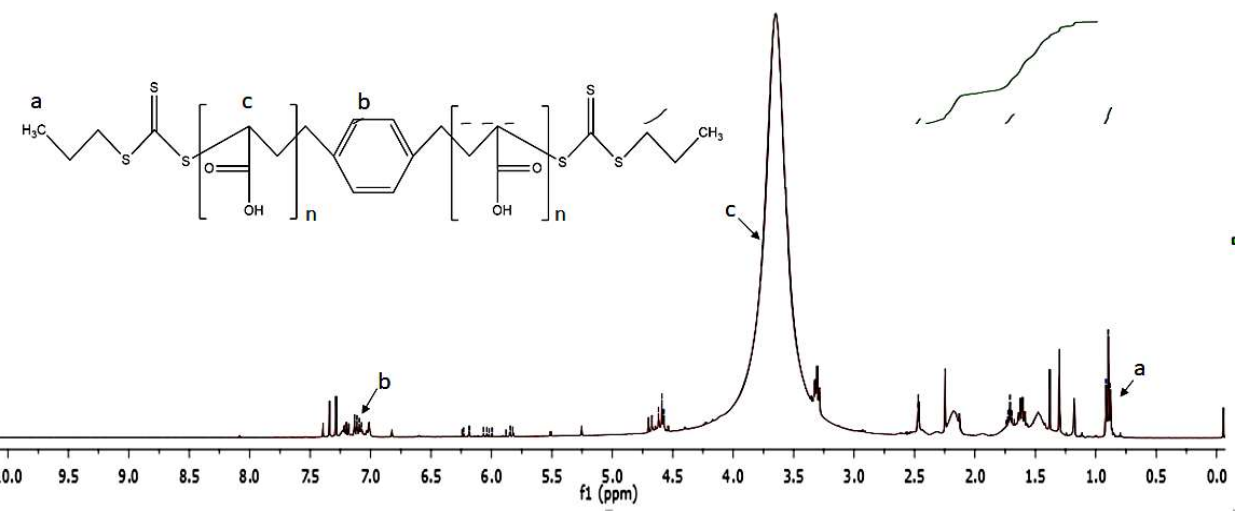

Fig.-2: H-NMR Spectra of Poly(acrylic acid) (PAA) in $\mathrm{D}_{2} \mathrm{O}$

1859 
RASĀYAN J. Chem.

Vol. 12 | No. 4 |1857 - 1863| October - December | 2019

\section{Properties of Hydrogel-CAuNPs-PAA}

The mixing of PAA solution into AuNPs solution produced the self-assembly of cross-linked polymer and AuNPs. The mixed solution showed unique properties, which is the color change of the solution when it was stimulated by different $\mathrm{pH}$. In an acidic condition, the solution showed a blue color and the color was change into red in alkaline condition. The swelling and deswelling mechanism of PAA which caused aggregation and disaggregation of AuNPs according to the environmental conditions explained the color changes. $^{7}$

The $\mathrm{pH}$ transition point (the turning point of the color change) of the polymer is between $\mathrm{pH} 4$ and 5 . As the $\mathrm{pH}$ increased, the polymer started to be unionized and undergoing phase changes from the swollen state into the shrunken state which results in aggregation of the AuNPs. This transition can be observed as the color of the solution changing from red to blue. The color change of AuNPs-PAA system showed reversibility, due to the swelling and shrinking of the responsive polymer. At $\mathrm{pH} 12$, the AuNPs-PAA spectrum shows a sharp plasmon band with a peak at $\sim 523 \mathrm{~nm}$. Decreasing $\mathrm{pH}$ caused the redshift at $\sim 600$ $\mathrm{nm}$, due to the coupling of the plasmon band in the nearby particles.

Cysteine is a non-essential amino acid that contains a sulfhydryl group. The sulfhydryl group of the cysteine was expected to bind to the surface of AuNPs. ${ }^{19}$ Cysteine was added into AuNPs-PAA system to increase the positive charge of the system caused by the positive charge of the amine group. The positive charges of the system could bind electrostatically to the negative charges of bacteria so that the bacteria can be detected using this sensor. The characterization of CAuNPs-PAA was carried out by measuring the zeta potential of each system, as shown in Table-1.

Table-1: Zeta Potential of the Different System

\begin{tabular}{c|c}
\hline System & Zeta Potential $(\mathrm{mV})$ \\
\hline AuNPs & $-21.7 \pm 2.4$ \\
\hline AuNPs-PAA & $-18.0 \pm 1.3$ \\
\hline CAuNPs-PAA & $-16.7 \pm 1.1$ \\
\hline
\end{tabular}

The optical properties of CAuNPs-PAA can be seen in Fig.-3. The addition of cysteine into AuNPs-PAA solution produced a red solution, whereas it appeared blue when the cysteine was added to AuNPs solution. The responsive polymer in AuNPs-PAA played the role of stabilizing the system by keeping the distance between nanoparticles.

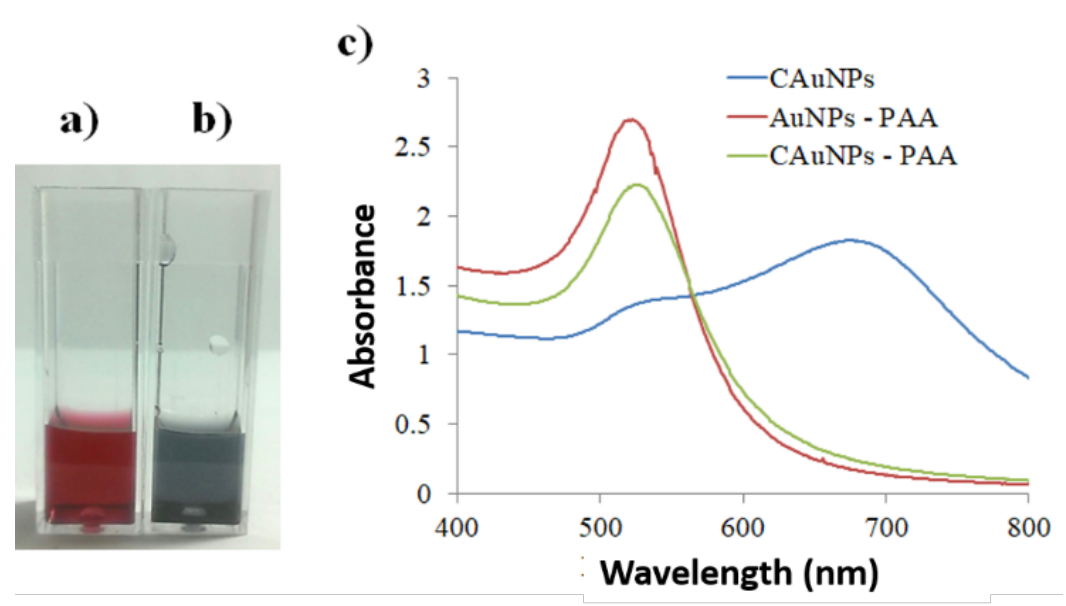

Fig.-3: (a) Picture of CAuNPs-PAA, (b) CAuNPs, (c) Spectra of the Different System

Responsive-hydrogel has been developed for biosensor devices. The gelling agent used is agarose which is stable at $\mathrm{pH} 4-10$ with a concentration of $0.25-1.0 \%$. The spectra of the synthesized hydrogel are shown in Fig.-4. 
RASĀYAN J. Chem.

Vol. 12 | No. 4 |1857 - 1863| October - December | 2019

The reversibility of the color change of hydrogel nanocomposite was also studied. Fig.-5 shows the clear color change of the hydrogel from red to blue and vice versa, up to three cycles of repetition. These color changes were related to the swelling and shrinking of the responsive polymer that cross-linked the AuNPs embedded in the hydrogel that tuned the disaggregation and aggregation of the gold nanoparticles when it was exposed to different $\mathrm{pH}$.

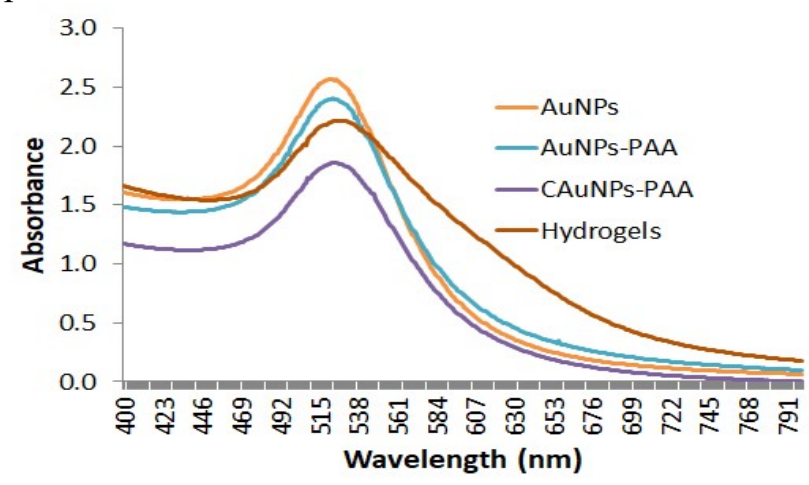

Fig.-4: The UV-Vis Absorbance Spectra of the Different Systems. The Spectra Show that the SPR Peaks at 522-525 nm
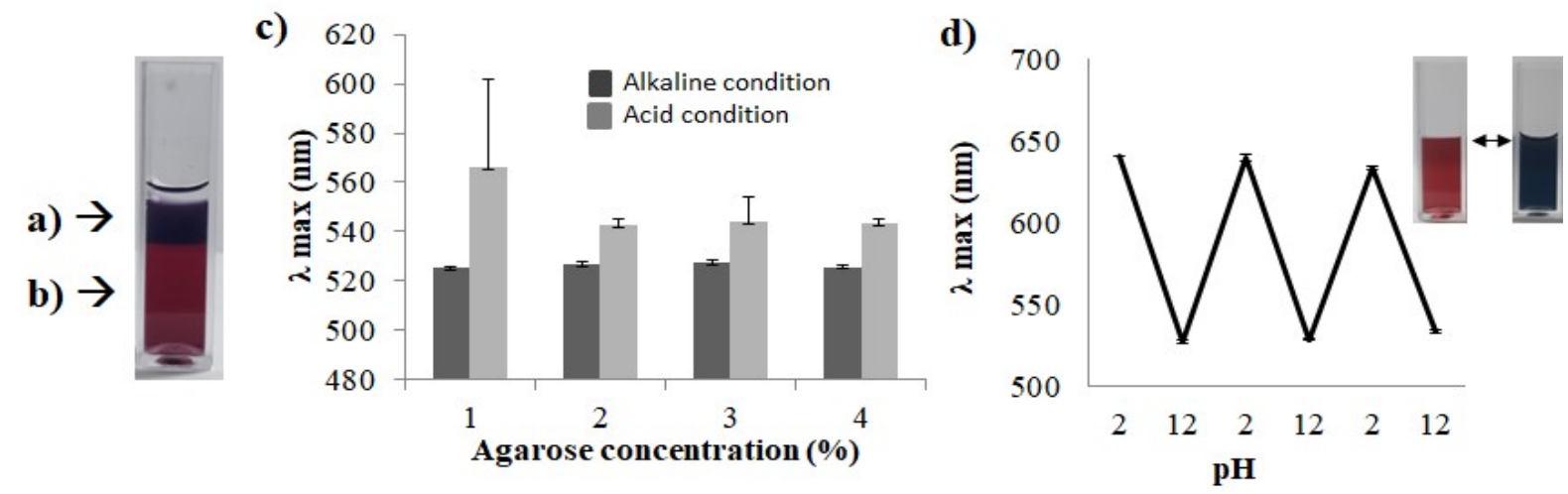

Fig.-5: (a) Hydrogel-CAuNPs-PAA in Acid and (b) Alkaline Condition, (c) the SPR Peaks of Hydrogel-CAuNPsPAA at Different Concentration, (d) the Reversibility of the CAuNPs-PAA Hydrogels in $\mathrm{pH} 12$ and $\mathrm{pH} 2$ (3 cycles, 3 Replication)

\section{Detection of Escherichia coli Using the Sensor System}

The hydrogel-AuNPS-PAA was then applied for detecting E. coli bacteria. At the $10^{-8} \mathrm{CFU} / \mathrm{mL}$ concentration of $E$. coli, the color of the hydrogel turned purple from red after 17 hours of incubation. The spectrophotometry analysis revealed that there are 3-5 nm shifts of the SPR peaks of the hydrogel after incubation with the bacteria (Fig.-6).

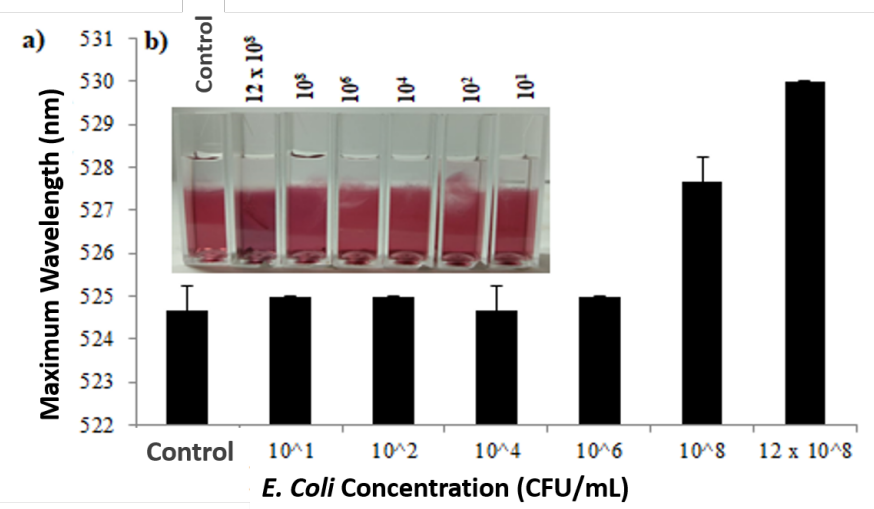

Fig.-6: The SPR Peaks of the Hydrogel-AuNPs-PAA After Incubation with Different Concentration of E. coli 
The interaction of the CAuNPs-PAA and the bacteria was observed using TEM (Fig.-7). The images showed there is a small aggregation of nanoparticles around the bacteria that possibly caused the color change of the solution.

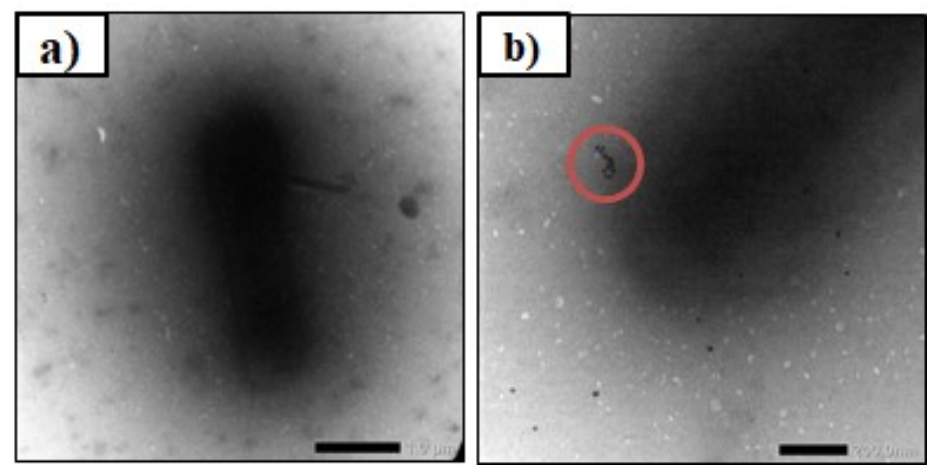

Fig.-7: (a) TEM Images of CAuNPs-PAA and E. coli at the low and (b) Higher Magnification

This result is in agreement with the previous study by Raj, et al. that reported detection of E. coli using cysteine capped gold nanoparticles through electrostatic adhesion between the negative charge of the bacteria and the positive potential of the cysteine. The colorimetric sensor of cysteine gold nanoparticles (CAuNPs) bond with E. coli and resulted in a color change from red to purple, with a shift of maximum peak of $10 \mathrm{~nm}^{19}$. The shift of SPR peak in this sensor system was expected to be higher so that the color change from red to blue can be observed clearly. The limited SPR peak shift in this study was produced probably because of the complicated structure of the responsive polymer around the gold nanoparticles that prevented the interaction between the cysteine and the bacteria directly.

\section{CONCLUSION}

The addition of PAA pH-responsive polymers into the cysteine gold-conjugate nanoparticle system results in a shift in the maximum wavelength which is accompanied by a clear color change from red to blue. The formed AuNPs-PAA and hydrogel-CAUNPs-PAA have the ability to change color with a swelling and deswelling mechanism. This nanocomposite hydrogel is highly potential to be developed as a nanosensor based on $\mathrm{pH}$ alterations.

\section{ACKNOWLEDGMENT}

The author would like to thank RISTEKDIKTI, the Indonesian Government for the research funding (Grant No.72.1/A.3-III/LPPM/III/2019).

\section{REFERENCES}

1. H.R. Culver, J.R. Clegg, and N.A. Peppas, Acc. Chem. Res., 50, 170(2017), DOI: 10.1021/acs.accounts.6b00533

2. S. Anniebell and S. Gopinath, Current Medicinal Chemistry, 25, 1433(2018), DOI: 10.2174/0929867324666170116123633

3. F. Muench, A. Solomonov, ACS Appl. Bio Mater., 2(2), 856(2019), DOI: 10.1021/acsabm.8b00702

4. D.R. Raj, S. Prasanth, T.V. Vineeshkumar, C. Sudarsanakumar, Optics Communications, 15(367), 102(2016), DOI: 10.1016/j.optcom.2016.01.027

5. A.B.Socorro, P.J. Rivero, M. Hernaez, J. Goicoechea, I.R. Matias and F.J. Arregui, In Smart Sensors, Actuators, and MEMS VII; and Cyber Physical Systems, 9517, 9517W(2015), DOI: $10.1117 / 12.2179970$

6. A. Pucci, G. Ruggeri, S. Bronco, F. Signori, F. Donati, M. Bernabò, F. Ciardelli, Progress in Organic Coatings, 72(1-2), 21(2011), DOI: 10.1016/j.porgcoat.2010.12.015

7. X.Y. Liu, F. Cheng, Y. Liu, W.G. Li, Y. Chen, H. Pan, H.J. Liu, J. Mater. Chem., 20, 278(2010), DOI: 10.1039/B916125B

8. C.D. Brubaker, T.M. Frecker, I. Njoroge, G.K. Jennings, D.E. Adams, In 8th European Workshop on Structural Health Monitoring, 5(2016), DOI: 10.1007/s00706-007-0648-8

HYDROGEL NANOCOMPOSITE 1862 
RASĀYAN J. Chem.

Vol. 12 | No. 4 |1857 - 1863| October - December | 2019

9. M. Qin, M. Sun, R. Bai, Y. Mao, X. Qian, D. Sikka, Y. Zhao, H.J. Qi, Z. Suo, X. He, Advanced Materials, 30(21), 1800468(2018), DOI: 10.1002/adma.201800468

10. Q. Chai, Y. Jiao, X. Yu, Gels, 3(1), 6(2017), DOI: 10.3390/gels3010006

11. P. Thoniyot, M.J. Tan, A.A. Karim, D.J. Young, X.J. Loh, Advanced Science, 2(1-2), 1400010(2015), DOI: $10.1002 / \mathrm{advs} .201400010$

12. K. Bharathi \& P. Pazhanisamy, Rasayan J. Chem., 11(4), 1721(2018), DOI: 10.31788/RJC.2018.1142072

13. J.P. Monteiro, S.M. Predabon, C.T. da Silva, E. Radovanovic, E.M. Girotto, Journal of Applied Polymer Science, 132(34), 42449(2015), DOI: 10.1002/app.42449

14. P. Zarrintaj, S. Manouchehri, Z. Ahmadi, M.R. Saeb, A.M. Urbanska, D.L. Kaplan, M. Mozafari, Carbohydrate Polymers, 187, 66(2018), DOI: 10.1016/j.carbpol.2018.01.060

15. Y. Liu, X. Han, L. He, Y. Yin, Angewandte Chemie, 51(26), 6373(2012), DOI: 10.1002/anie. 201201816

16. M. Tejaswi, M.C. Rao, R.K.N.R. Manepalli, B.T.P. Madhav, P. Pardhasaradhi, G. Giridhar, K. Pandian, and V.G.K.M. Pisipati, Rasayan J. Chem., 10(1), 69(2017), DOI: 10.7324/RJC.2017.1011571

17. A.M. Bivigou-Koumba, J. Kristen, A. Laschewsky, P. Müller-Buschbaum, C.M. Papadakis, Macromolecular Chemistry and Physics, 210(7), 565(2009), DOI: 10.1002/macp.200800575

18. K. Sivaram, M.C. Rao, G. Giridhar, M. Tejaswi, B.T. Madhav, V.G. Pisipati, R.K. Manepalli, Rasayan J. Chem., 10(1), 697(2017), DOI: 10.7324/RJC.2017.1011539

19. V. Raj, A.N. Vijayan, K. Joseph, Sensing and Bio-sensing Research, 5, 33(2015), DOI: 10.1016/j.sbsr.2015.05.004

[RJC-5209/2019] 